\title{
Heterotopic pancreas: a difficult diagnosis
}

A 45-year-old man was admitted to our hospital complaining of epigastric pain and nausea for 2 days. He had no history of systemic disease. Laboratory tests at admission, including amylase, were normal except for a $12100 / \mathrm{mm}^{3}$ leucocyte count (89\% polymorphonuclear). Abdominal ultrasonography revealed an irregular, hypoechoic solid lesion of $37 \times 28 \mathrm{~mm}$, and computed tomography scan showed a 37-mm, thick-walled, extraluminal cystic lesion.

Gastroscopy revealed a submucosal lesion at the antrum of the stomach with a necrotic eschar on its surface ( $\bullet$ Fig. 1; - Video 1). Endoscopic ultrasonography showed a heterogeneous lesion suggesting muscular layer necrosis. The patient was successfully treated surgically by subtotal gastrectomy. Pathological examinations confirmed a diagnosis of aberrant pancreas ( $\bullet$ Fig. 2 ).

Heterotopic pancreas is the presence of pancreatic tissue lying outside of its normal location and lacking anatomic or vascular connections with the pancreas [1]. It is located in the antrum in $85 \%-95 \%$ of cases, and it is usually asymptomatic but may become clinically evident depending on the size, location, and the pathological changes [2]. In some cases, because the findings on imaging studies are not specific for aberrant pancreas, its preoperative definitive diagnosis is difficult [3]. The definitive diagnosis of aberrant pancreas is attained on histopathological examination and it should always be considered in the differential diagnosis of gastric masses.

\section{Video 1}

Gastroscopy revealed a submucosal lesion at the antrum of the stomach with a necrotic eschar on its surface.

\section{Competing interests: None}

Endoscopy_UCTN_Code_CCL_1AB_2AC_3AB

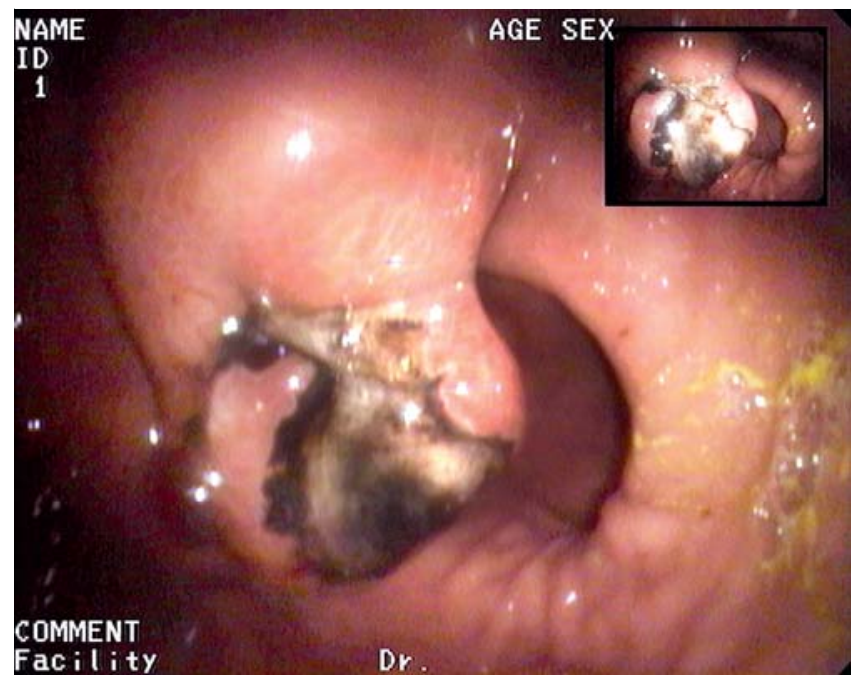

Fig. 1 Gastroscopy revealed a submucosal lesion at the antrum of the stomach.

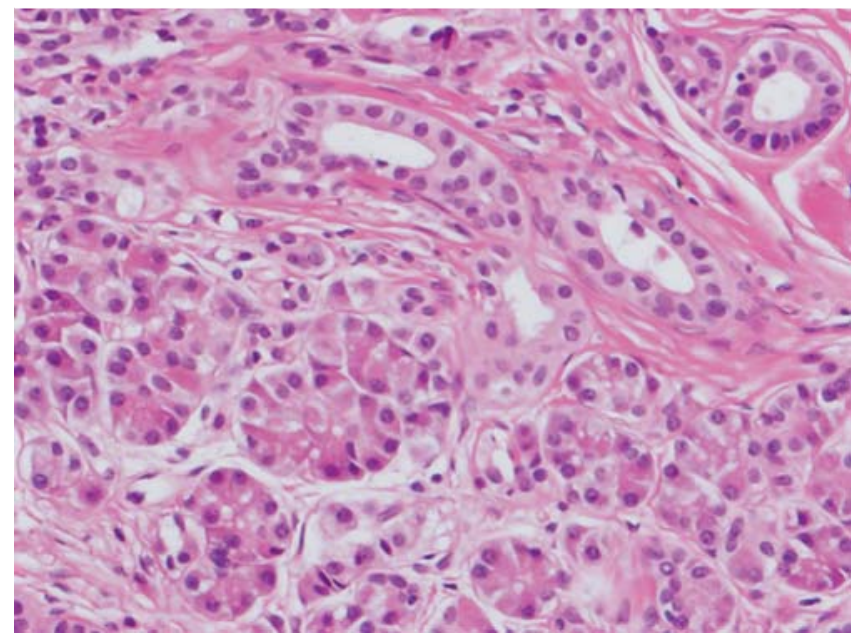

Fig. 2 Pathological examination confirmed a diagnosis of aberrant pancreas.

\section{G. Payeras ${ }^{1}$, C. Castellón², J. De Jaime², R. Barranco ${ }^{1}$, A. Calvache ${ }^{1}$, P. Castro ${ }^{1}$ \\ 1 Digestive Endoscopy Unit, Department of Gastroenterology, Hospital Infanta Elena, Madrid, Spain \\ 2 Department of Surgery, Hospital Infanta Elena, Madrid, Spain}

\section{References}

1 Akaraviputh T, Manuyakurn A, Lohsiriwat V. Diagnosis by endoscopic ultrasound of a large aberrant pancreas mimicking malignant gastrointestinal stromal tumor of the stomach. Endoscopy 2009; 41: 573

2 Kobayashi S, Okayama Y, Hayashi $K$ et al. Heterotopic pancreas in the stomach which caused obstructive stenosis in the duodenum. Intern Med 2006; 45: 1137-1141

3 Christodoulidis G, Zacharoulis D, Barbanis S et al. Heterotopic pancreas in the stomach: a case report and literature review. World J Gastroenterol 2007; 13: 6098-6100
Bibliography

DOI $10.1055 / \mathrm{s}-0029-1243988$

Endoscopy 2010; 42: E121

(c) Georg Thieme Verlag KG Stuttgart · New York . ISSN 0013-726X

Corresponding author

G. Payeras, MD

Digestive Endoscopy Unit

Department of Gastroenterology

Sanatorio San Fco. Asis

Joaquin Costa 28 Madrid

Madrid 28002

Spain

Fax: +34-91-4113839

gpayeras@yahoo.es 